\title{
Pobreza e Diversidades Locacionais: Uma Investigação Empirica para o Brasil a partir do Censo 2010
}

\author{
Laura de Carvalho Schiavon $^{1}$ (D) | Ana Maria Hermeto Camilo de Oliveira ${ }^{2}$ \\ ${ }^{1}$ Professora da Faculdade de Economia, Universidade Federal de Juiz de Fora, Juiz de Fora, MG, Brasil. E-mail: \\ lauracschiavon@gmail.com \\ 2 Professora do Departamento de Ciências Econômicas, Universidade Federal de Minas Gerais, Belo Horizonte, MG, \\ Brasil. E-mail: ahermeto@cedeplar.ufmg.br
}

\begin{abstract}
RESUMO
Este trabalho realiza um estudo da pobreza relativa domiciliar nos municípios brasileiros para diferentes contextos socioeconômicos, visando investigar a importância da ponderação das variáveis locacionais, analisar a heterogeneidade da relação entre renda domiciliar per capita e características domiciliares e locacionais ao longo da distribuição de renda e estudar os determinantes domiciliares e locacionais da pobreza relativa. Para tanto, são aplicadas diferentes metodologias, Mínimos Quadrados Ordinários, modelos hierárquicos e regressão quantílica. Os resultados reportam a sensibilidade das estimações à inclusão de características municipais nos modelos e a significativa correlação destas com renda, a heterogeneidade da relação entre renda domiciliar per capita e características domiciliares/locacionais ao longo da distribuição de renda e a resposta das estimações à presença de outliers. Os resultados sugerem que políticas de promoção do desenvolvimento humano e de fortalecimento do mercado de trabalho formal brasileiro constituem importante estratégia de redução da pobreza.
\end{abstract}

\section{PALAVRAS-CHAVE}

Pobreza, Economia Regional, Microeconometria

Poverty and Regional Differences: An Empirical Analysis for Brazil using 2010 Census

\section{ABSTRACT}

The article studies relative household poverty in Brazilian municipalities of different socioeconomic backgrounds. The study aims at understanding the role of regional disparities on poverty. First, we focus on methodological aspects, including the discussion about omitted variable bias and an examination of sensitivity of results to changes in methods and assumptions. We also exploit the great heterogeneity in the correlation between local characteristics and income. Finally, we discuss the poverty determinants, comprising variables at household and municipal levels. We use different methodologies: Ordinary Least Squares (OLS), hierarchical models and quantile regression. The results suggest that public policies focused on the promotion of the human development and of the formal labor market are of great importance in reducing poverty.

\section{KEYWORDS}

Poverty, Regional Economics, Microeconometrics

\section{CLASSIFICAÇÃO JEL}

I32, R20 


\section{Introdução}

Pertinente desafio do desenvolvimento socioeconômico nacional, os altos niveis de pobreza no Brasil, embora tenham sofrido redução nas últimas décadas, perduram em níveis muito elevados, o que reitera a necessidade do estudo de seus determinantes. Esses têm efeitos distintos segundo características dos indivíduos e das regiões onde eles habitam (Chetty et al., 2014; Chetty et al., 2016). Nessa tônica, este estudo investiga a relação entre desenvolvimento socioeconômico local e renda domiciliar, com enfoque sobre pobreza relativa no Brasil explorando o Censo de 2010 (IBGE, 2010). A redução da pobreza e da desigualdade no país a partir dos anos 2000 ocorreu em resposta às transformações no mercado de trabalho, como o aumento da formalização, o crescimento real do salário mínimo e a redistribuição dos rendimentos do trabalho, e à criação/expansão dos programas de transferências governamentais (IPEA, 2013; Dedecca, 2015). Movimento similar foi observado na América Latina no período (Lustig et al., 2013).

As análises da evolução da condição de privação na literatura são predominantemente desenvolvidas considerando o contexto econômico em nível nacional e/ou fatores domiciliares. As diferenças regionais, no entanto, são vastas e determinantes no delineamento de políticas públicas no Brasil. Este trabalho traz como principal contribuição o estudo da pobreza relativa domiciliar nos municípios e o entendimento do papel das características locacionais na determinação da condição de privação dos domicílios brasileiros. Adicionalmente, propõe um novo enfoque sobre pobreza relativa, considerando como pobres aqueles cuja renda domiciliar per capita é inferior ao segundo decil de renda nacional ${ }^{1}$, e pondera a heterogeneidade da relação entre renda domiciliar per capita e características domiciliares e locacionais ao longo da distribuição de renda.

Este artigo se desenvolve sobre três objetivos centrais. O primeiro, consiste na investigação da importância da ponderação das variáveis locacionais e da interdependência regional no estudo do comportamento da renda. O segundo, na análise da heterogeneidade da relação entre renda domiciliar per capita e características domiciliares e locacionais ao longo da distribuição de renda. O terceiro, no estudo dos determinantes domiciliares e locacionais da pobreza relativa e no entendimento de como dissimilaridades regionais alteram padrões relativos à pobreza. Para tanto, são exploradas as informações detalhadas em nivel municipal e domiciliar disponíveis apenas através dos microdados do último Censo Demográfico (IBGE, 2010), em conjunto com as Estatísticas do Registro Civil (IBGE, 2010) e o estudo Regiões de Influência das Cidades (IBGE, 2007).

Primeiramente, verifica-se a sensibilidade das estimações à inclusão de caracte-

\footnotetext{
${ }^{1}$ Por este critério e a partir da utilização dos dados do Censo Demográfico (IBGE, 2010), são considerados pobres aqueles domicílios cuja renda domiciliar per capita era igual ou menor a 195 reais por mês. Esse corte é semelhante a outros utilizados no período por estudos e órgãos oficiais para o desenho de políticas públicas, como a classificação utilizada pela Secretaria de Assuntos Estratégicos (2011).
} 
rísticas municipais nos modelos e, principalmente, a significativa correlação destas com renda, evidenciando a existência de viés de variável omitida em especificações nas quais não há controles locacionais. Adicionalmente, a heterogeneidade da relação entre renda domiciliar per capita e características domiciliares e locacionais ao longo da distribuição de renda é explorada neste trabalho. Foram estimados separadamente modelos para amostras de domicílios em diferentes faixas de renda, para as quais os resultados são significativamente distintos. Da mesma forma, as estimações se mostraram sensíveis à presença de outliers, como observado a partir da comparação entre diferentes metodologias. Verifica-se que a análise da relação entre aspectos domiciliares e locacionais e para diferentes faixas de renda desta faz-se muito informativa.

Este trabalho engloba extensa análise dos determinantes domiciliares e locacionais de renda, com enfoque nos domicílios relativamente mais pobres. Estão mais sujeitos a privações domicílios com chefes do sexo feminino, mais jovens, de cor preta ou parda, sem acompanhantes ou cônjuges, com menor escolaridade ou desempregados, assim como domicílios com maior número de moradores ou localizados em áreas rurais. Estima-se que aproximadamente $35 \%$ da variância da renda domiciliar per capita é explicada pelas diferenças intermunicipais. Apresentam menor renda per capita domicílios localizados em municípios mais populosos, com maior taxa de fecundidade e mortalidade, menor percentual de moradores com ensino superior, maior taxa de desemprego e de trabalhadores informais. No tocante ao grau de centralidade, tendem a apresentar menor renda per capita domicílios localizados em municípios com maior grau de centralidade, à exceção daqueles pertencentes às grandes metrópoles, resultado que pode estar relacionado à resposta da renda ao custo de vida local. Verifica-se, por último, que domicílios pobres e ricos tendem a se concentrar e a apresentar maior renda em municipios com maior grau de desigualdade. Dessa forma, contribui-se para o estudo de renda no Brasil e para o delineamento de políticas públicas de desenvolvimento regional e combate à pobreza ao analisar os diferentes aspectos relativos aos determinantes locacionais de renda.

\section{Pobreza Relativa}

Segundo Barros, Henriques e Mendonça (2000), a pobreza é historicamente provocada pela desigualdade no país. Entre os anos de 1960 e 1990, respondeu ligeiramente às tendências de crescimento econômico nacional, cujos efeitos foram reduzidos devido à má distribuição de renda (Barros, Mendonça, 1995; Arbache, 2003). Segundo a análise de Ravallion (2012) para economias em desenvolvimento, um elevado nivel de pobreza prejudica o crescimento e simultaneamente reduz o impacto positivo deste sobre a renda dos mais pobres, o que explica parte da persistência dos diferentes níveis de privação entre os países. A partir da década de 90, observou-se redução da proporção de pessoas abaixo da linha de miséria (Neri, 2007). No referente à trajetória da desigualdade de renda em nível nacional, Ferreira, Leite e Litchfield 
(2006) revelam que, alavancada na década de 60, encontrou-se relativamente estável em altos níveis entre 1970 e 2000, apresentando, posteriormente, acelerada redução.

A partir dos anos 2000, observou-se uma redução na desigualdade na maioria dos países latino-americanos. No Brasil, na Argentina e no México essa redução foi promovida especialmente pela redução do retorno da educação no mercado de trabalho e pelo crescimento dos programas de transferências de renda governamentais (Lustig et al., 2013; Souza et al., 2019). Lustig et al. (2013) destacam que a redução da pobreza provocada pelos programas de transferências de renda foi parcialmente reduzida pela progressividade dos impostos indiretos nos países da América Latina, especialmente no Brasil e na Bolívia. Entre 2000 e meados dos anos 2010, o Brasil vivenciou um crescimento no número de empregos, nas políticas de renda e nos gastos públicos, refletidos no aumento da renda do trabalho, da previdência e do Bolsa Família (IPEA, 2013; Dedecca, 2015; Souza et al., 2019). Este movimento foi maior em termos relativos para os mais pobres, contribuindo simultaneamente para a redução da pobreza e da desigualdade no país no período, ainda que em menor intensidade a partir de 2012 (IPEA, 2013).

A pobreza pode ser subdividida em três perfis: (1) decorrente de baixa renda per capita local; (2) decorrente de alta desigualdade, apesar da coexistência de nível elevado de renda; (3) decorrente de má distribuição de renda, apesar do estabelecimento de um nivel de renda per capita suficiente para atender às necessidades da população (Rocha, 2006). O Brasil encontra-se nesse terceiro grupo, sendo a desigualdade a principal causa de pobreza (Barros et al., 2000; Assouad et al., 2018).

De especial interesse nessa análise, ascende a diferenciação entre pobreza absoluta, relacionada à noção de sobrevivência e satisfação de necessidades básicas, e pobreza relativa, definida diretamente a partir de referenciais sociais. Segundo Soares (2009), a concepção relativa trata a pobreza como uma condição que depende da renda da sociedade como um todo, enquanto a pobreza absoluta baseia-se em critérios fixos. Dessa forma, a perspectiva relativa faz-se pertinente ao considerar pobres aqueles cujo padrão de vida é insuficiente para o nível determinado sócio e historicamente, como definido por Barros, Henriques e Mendonça (2000). A abordagem das privações relativas ganha destaque com a ampliação do conceito de pobreza, tendendo a abarcar um conjunto cada vez maior de indicadores, e com a negação de uma determinação estática de pobreza. Townsend (1962) afirma que uma definição estrita de pobreza só pode ser dada se considerados os recursos sociais e emocionais de uma sociedade em um período de tempo, sendo, portanto, uma situação de privação relativa. Ademais, Townsend (1993) argumenta que as necessidades se modificam rapidamente, seguindo as tendências de mudança das sociedades, assim como sua relação com renda e outros indicadores, sendo a pobreza dinâmica. Sob a ótica relativa, amplia-se, portanto, a perspectiva social, associando à pobreza a privação de meios para a atuação em sociedade de acordo com seus próprios referenciais de consumo, cidadania, independência e inclusão. 
No Brasil, a elevada incidência de pessoas pobres em termos absolutos tendência os estudos à adoção dessa abordagem. Porém, a certificação do papel central da desigualdade como causa da pobreza no país reitera a aplicação da concepção relativa, que incorpora, dentre outros, o fator distributivo (Barros et al., 2000; Assouad et al., 2018). As discussões e contradições acerca dos conceitos de pobreza permitem concluir que, da perspectiva adotada, derivam possibilidades particulares de análise, não havendo hierarquia dentre os enfoques, mas adequabilidade à proposta de pesquisa. Optou-se pela utilização da ótica relativista neste trabalho devido à amplitude trazida para a compreensão das privações, como discutido nessa seção. A identificação dos domicílios pobres em termos relativos foi realizada a partir de um enfoque monetário, sendo considerados pobres aqueles domicílios cuja renda domiciliar per capita encontra-se abaixo do segundo decil de renda nacional. A adoção de um critério fixo baseado em renda, amplamente utilizado na literatura nacional e internacional, e facilmente aferível em diferentes contextos favorece a comparabilidade entre estudos e o desenho e a avaliação de políticas públicas.

\section{Base de dados e metodologia}

Este trabalho realiza um estudo dos aspectos domiciliares e locacionais da pobreza sob a ótica da renda no Brasil a partir de dados do Censo Demográfico (IBGE, 2010), das Estatísticas do Registro Civil (IBGE, 2010), e do estudo Regiões de Influência das Cidades (IBGE, 2007). Metodologicamente, foi desenvolvida uma análise descritiva dos dados e estimados modelos de regressão por mínimos quadrados ordinários, regressão quantílica e modelagem hierárquica, sendo extraídas relações de correlação entre renda domiciliar per capita e características domiciliares e locacionais.

São considerados pobres aqueles cuja renda domiciliar per capita encontra-se abaixo do segundo decil de renda nacional, correspondente à renda de 195 reais em 2010, segundo o Censo Demográfico (IBGE, 2010). Esse corte é próximo de outros apresentados na literatura e coerente com o contexto socioeconômico nacional no período. Aproxima-se, em especial, da classificação apresentada pela Secretaria de Assuntos Estratégicos (2011), para a qual domicílios com renda per capita de até 195 reais são considerados pobres ou vulneráveis. Tais critérios são desenhados para análises em nível nacional.

O estudo da relação entre fatores locacionais e pobreza, determinada segundo critérios de renda, implica a adoção de um critério invariante de privação entre as regiões para garantir a comparabilidade entre as mesmas. O uso de um único valor permite a comparação com parcela importante dos trabalhos empíricos no tema e com critérios de determinação de políticas públicas em nível nacional, que usualmente adotam um referencial único determinado em termos absolutos. A determinação de diferentes linhas de corte municipais a partir da distribuição da renda domiciliar per capita local não permitiria a comparação desenvolvida entre localidades, uma vez que sempre seria classificado como pobres $20 \%$ da população de cada município. Nesse caso, 
as análises como conduzidas incorreriam necessariamente em problema de simultaneidade. A fim de evitar que a relação entre características locacionais e pobreza seja contaminada por diferenças no custo de vida, são inseridos controles que visam captar tal variação.

\subsection{Base de dados e variáveis}

A base de dados foi construída a partir das seguintes fontes, desenvolvidas e/ou divulgadas pelo Instituto Brasileiro de Geografia e Estatística (IBGE): microdados da amostra e dados do universo do Censo Demográfico 2010, Estatísticas do Registro Civil 2010, e dados do estudo Regiões de Influência das Cidades (REGIC, 2007). As variáveis se subdividem em dois grupos: variáveis domiciliares, que contém aquelas relativas ao domicílio diretamente, e variáveis locacionais, que contém aquelas relativas ao município no qual o domicílio está situado.

As análises são desenvolvidas sobre a base de dados completa e três bases derivadas desta. A primeira, contém os domicílios com renda domiciliar per capita até o segundo decil de renda em nível nacional, os $20 \%$ mais pobres. A segunda, contém os domicílios com renda domiciliar per capita entre o quarto e o sexto decil, cuja renda se aproxima da mediana. A terceira, contém os domicílios com renda domiciliar per capita acima do oitavo decil, os $20 \%$ mais ricos. Tais recortes são motivados pela acentuada disparidade de renda intra e inter-regional no Brasil e pelas diferentes características dos grupos de renda. Em todos os modelos, o logaritmo da renda ${ }^{2}$ domiciliar per capita é utilizado como variável dependente.

A escolha das variáveis independentes do domicílio foi baseada na literatura que explora como principais determinantes da condição de privação: as características do chefe relacionadas direta ou indiretamente à renda do trabalho devido sua importância relativa na renda domiciliar, como idade, sexo, etnia, nível educacional e condição de ocupação; a estrutura familiar, sendo famílias uniparentais mais vulneráveis a choques negativos; e a localização do domicílio em área urbana ou rural, que apresentam diferentes dinâmicas econômicas e custo de vida, em geral (Barros et al., 1997; Jalan, Ravallion, 2000; Hulme et al., 2001; Rocha, 2006; Ferreira et al., 2006; Khandker, 2009).

Como variáveis independentes domiciliares, foram utilizadas as seguintes variáveis referentes ao chefe do domicílio: $\mathrm{Sexo}^{*}{ }^{3}$, que assume valor 0 para homens e 1 para mulheres; Faixa Etária*; Cor*, que assume valor 0 para brancos e amarelos, 1 para negros e 2 para pardos; e Companheiro*, igual a 0 se o chefe de domicílio vive em companhia de um cônjuge ou companheiro e igual a 1 caso contrário; Estudo*, correspondente a categorias de anos de estudo formal; e Emprego*, que assume valor

\footnotetext{
${ }^{2}$ Foram ponderados rendimentos monetários e não monetários oriundos de diferente fontes, incluindo aposentadoria ou pensão de instituto de previdência oficial, Programa Social Bolsa Família, rendimentos de outros programas sociais ou de transferência, aluguel e aposentadoria de previdência privada.

$3 *$ Fonte: microdados da amostra do Censo Demográfico (IBGE, 2010); ** Fonte: dados do universo do Censo Demográfico (IBGE, 2010); *** Fonte: Estatísticas do Registro Civil (IBGE, 2010)
} 
1 se desempregado e 0 caso contrário. Ademais, são incluídos como controles o número de Moradores e a variável chamada Urbrur*, igual a 1 quando o domicílio está em área urbana e 0 caso contrário.

Os municípios foram caracterizados a partir de seu nível desenvolvimento socioeconômico via medidas de desigualdade de renda, desigualdade de oportunidades e caracterização do mercado de trabalho, bem-estar, tamanho e importância regional/nacional do município (Jalan, Ravallion, 2000; Hulme et al., 2001; Fontes, 2006; Soares, 2009; Haughton, Khandker, 2009, Fryer, Katz, 2013). Pertencem ao grupo de variáveis locacionais, consideradas em nível municipal: logaritmo natural da população municipal (População**); taxa de mortalidade do município por mil habitantes (Mortalidade***); taxa de fecundidade (Fecundidade**); percentual da população, acima de 24 anos, com ensino superior completo ou maior nível de escolaridade (Formado**); percentual de desempregados no município (Desempregados**), ponderando apenas pessoas com 10 anos ou mais; e percentual de pessoas ocupadas, com 10 anos ou mais, atuantes no setor informal (Informal**). Além das variáveis descritas, foram utilizados o índice de Gini (Gini), uma medida de dispersão relativa da renda, e o mesmo elevado ao quadrado (Gini2). E, em busca de uma caracterização econômica mais complexa dos municípios, a classificação do estudo Regiões de Influência das Cidades (REGIC, 2007), que caracteriza o município segundo seu nível de centralidade. A população e a classificação do nível de centralidade ${ }^{4}$ do município REGIC em conjunto com a dummy se o domicílio está situado em área urbana ou rural atuam como proxies para custo de vida.

\subsection{Mínimos Quadrados Ordinários}

Primeiramente, foram estimados modelos lineares utilizando o método dos Mínimos Quadrados Ordinários (MQO). Esta é uma metodologia amplamente conhecida e aplicada, sendo, por tal motivo, escolhida para uma investigação inicial. Nesse trabalho são assumidas como hipóteses centrais a relevância dos aspectos regionais, apresentados em nível municipal, e a não independência das observações intramunicipalmente. Desse modo, optou-se pela estimação de um modelo pelo método dos mínimos quadrados com variância robusta a clusters, formados pelos municípios, mais conservador. A utilização de variáveis no modelo cujo valor não se altera para observações pertencentes ao mesmo grupo justifica a utilização de variância robusta.

\subsection{Modelos hierárquicos}

Partindo do pressuposto de que pobreza relativa é resultante não somente de fatores domiciliares, como também de fatores locacionais, este trabalho explora a metodologia de modelos hierárquicos lineares (MHL), relevantes quando o pressuposto de independência intragrupos das observações não é observado (Hox, 1998). Nos mo-

\footnotetext{
${ }^{4}$ Para maiores detalhes sobre as classes, ver publicação Regiões de Influência das Cidades (IBGE, 2007)
} 
delos hierárquicos, a variável resposta, $Y_{i j}$, renda domiciliar per capita, é obtida ao menor nível de agregação, domicílio, estando sujeita aos preditores de ambos os níveis, domiciliar e municipal. As variáveis dependentes, por sua vez, subdividem-se entre os dois níveis. O primeiro nível, representado pela matriz $X_{i j}$, cujas entradas são os valores das variáveis domiciliares para cada domicílio i pertencente ao município j. E o segundo nível, dado pela matriz $Z_{j}$, formada pelas variáveis municipais para cada localidade $\mathrm{j}$. A partir das matrizes descritas, tem-se o modelo para o menor nível de agregação descrito como:

$$
Y_{i, j}=\beta_{0, j}+\beta_{1, j} X_{i, j}+e_{i j}
$$

onde $\beta_{0, j}$ é o vetor de interceptos aleatórios e $\beta_{1, j}$ é a matriz de coeficientes aleatórios para cada variável domiciliar segundo o agrupamento j. Os parâmetros $\beta_{0, j}$ e $\beta_{1, j}$ são determinados a partir das variáveis municipais $Z_{j}$, como se segue:

$$
\begin{aligned}
& \beta_{0, j}=\gamma_{0,0}+\gamma_{0,1} Z_{j}+u_{0 j} \\
& \beta_{1, j}=\gamma_{1,0}+\gamma_{1,1} Z_{j}+u_{1 j}
\end{aligned}
$$

Os modelos hierárquicos foram estimados por Máxima Verossimilhança (MV), cujos estimadores são consistentes e assintoticamente eficientes para amostras suficientemente grandes nos dois níveis. Como primeira estimação por modelagem hierárquica, foi realizada uma análise da variância (ANOVA) com efeitos aleatórios, consistindo em um modelo hierárquico em dois níveis sem variável explicativa, chamado de modelo nulo (intercept-only model) (Hox, 1995). Nesse, é possível analisar o grau de correlação das observações entre os agrupamentos a partir das variâncias intragrupos e intergrupos. A variância desse modelo pode ser decomposta na variância $\tau_{00}$ entre os municípios, correspondente à variância dos resíduos de maior nível de agregação, e na variância domiciliar $\sigma^{2}$, correspondente à variância dos resíduos de menor nível $e_{i j}$. Desse modo, calcula-se o Coeficiente de Correlação Intraclasse (ICC), $\rho$, que consiste na parcela da variância total explicada pela variância intergrupos $\tau_{00}$ (Hox, 1995).

$$
\rho=\frac{\tau_{00}}{\tau_{00}+\sigma^{2}}
$$

Quanto maior o Coeficiente de Correlação Intraclasse, menor a participação da variância intragrupo $\sigma^{2}$ na variância total e, portanto, maior o grau de correlação entre os domicílios de um mesmo município. 


\subsection{Modelos de regressões quantilicas}

A literatura aponta a presença de outliers em dados relativos a renda como algo recorrente. Estes afetam fortemente os resultados para toda a amostra e em menor grau os resultados para as subamostras das faixas de renda que compreendem os extremos da distribuição. As metodologias utilizadas anteriormente consistem em estimações relativas à média, de toda a amostra ou das subamostras, tornando os coeficientes estimados potencialmente enviesados na presença de outliers. Diferentemente dos outros métodos explorados, a regressão quantílica estima o efeito das covariáveis sobre os quantis da variável dependente, sendo robusta a observações discrepantes (Tian e Chen, 2006).

A regressão quantílica consiste na estimação de modelos lineares condicionais para quantis $\theta$ da variável dependente $Y_{i j}$, no caso, renda domiciliar per capita. Um quantil $\theta$ é definido como o menor valor da variável dependente tal que a proporção de observações abaixo deste, dada pela função de distribuição acumulada $F($.), seja igual ou maior ao valor $\theta$ do percentil, como representado abaixo.

$$
\begin{gathered}
Q_{\theta}(Y)=\inf \{Y: F(Y) \geq \theta\} \\
Q_{\theta}(Y \mid X)=X^{\prime} \beta_{\theta}
\end{gathered}
$$

Desse modo, são estimados quantis da amostra condicionais às variáveis independentes. Os coeficientes estimados $\beta_{\theta k}$ para cada variável $x_{k}$ podem ser interpretados diretamente como o efeito marginal de uma variação de $x_{k}$ sobre o quantil $Q_{\theta}$ estimado. São estimadas regressões para os decis limítrofes das subamostras trabalhadas, segundo, quarto, sexto e oitavo decil, sob a especificação restrita e irrestrita.

\section{Resultados}

Essa seção discute os resultados deste trabalho, apresentando primeiramente as estatísticas descritivas e posteriormente os resultados das regressões.

\subsection{Estatísticas descritivas}

As Tabelas 1 e 2 apresentam as estatísticas descritivas das variáveis domiciliares e locacionais, respectivamente, sendo informados a média e o desvio-padrão. Os domicílios brasileiros apresentam renda domiciliar per capita de, aproximadamente, 945 reais mensais em 2010. A disparidade entre as rendas médias de cada grupo de observações retorna o elevado nível da desigualdade de renda no país e seu impacto sobre a pobreza. Dentre os $20 \%$ mais pobres, a desigualdade de renda é grande em relação à média, fator de agravamento da condição de privação de parte dos domicílios pertencentes a este grupo. No tocante ao sexo, observa-se que aproximadamente 39\% 
dos chefes de domicílio são mulheres, média em torno da qual se encontram os grupos analisados. Segundo Barros et al. (1997), o número de domicílios chefiados por mulheres está aumentando, constituindo um grupo fortemente heterogêneo, crescente especialmente em áreas urbanas e com rendimentos per capita menores. Quanto à idade do chefe, domicílios com renda per capita inferior ao segundo decil da distribuição apresentam chefes mais jovens. A proporção de chefes brancos e amarelos aumenta progressivamente com maiores decis de renda, ao contrário do que ocorre com a proporção de chefes pardos e negros. Segundo Osório (2003), há uma tendência ao que ele chama de "embranquecimento", que seria a preferência por declarar-se branco, especialmente entre as classes mais altas, o que sugere que a proporção de chefes brancos provavelmente é mais sobrestimada quanto maior for o nivel de renda em questão.

A relação entre renda e companheiro/cônjuge, não se mostra muito delineada a partir das estatísticas descritivas. O oposto ocorre com o número de moradores por unidade orçamentária, que tende a reduzir à medida que são observados domicílios com renda per capita mais elevada. Por outro lado, domicílios com renda per capita mais baixa são predominantemente chefiados por pessoas com menor grau de escolaridade, o que é revertido quando da análise de domicílios com rendas mais elevadas. Este resultado confirma o discutido por Ferreira et al. (2006), que afirmam ser o principal determinante da desigualdade de renda domiciliar a diferença relativa à escolaridade do chefe. Quanto à situação empregatícia dos chefes de domicílio, apenas pequeno percentual encontra-se desempregado, 4,3\%, o que ocorre com frequência maior dentre os mais pobres. Segundo Rocha (2006), instabilidades relativas ao rendimento do chefe de domicílio, devido à sua elevada participação percentual no orçamento domiciliar, são fatores determinantes da condição de vulnerabilidade dos moradores dos domicílios. Dado o elevado grau de urbanização nacional, apenas 14\% dos domicílios se encontram em área rural, sendo a proporção de domicílios localizados na zona rural maior dentre os pobres.

A Tabela 2 reporta as estatísticas descritivas das variáveis locacionais. Os domicílios encontram-se em municípios com aproximadamente 1,3 milhão de habitantes, o que não revela a população média dos municípios brasileiros, mas uma tendência à concentração de domicílios em municípios com população em torno dessa. Renda domiciliar per capita e habitantes do município são positivamente correlacionados, apresentando grande variabilidade intragrupo. A taxa de mortalidade por mil habitantes apresenta também média crescente em relação aos quantis de renda analisados, com altos desvios-padrões para os grupos considerados. A taxa de fecundidade, outro indicador parcial de bem-estar municipal, revela-se, em média, negativamente correlacionada com a renda.

O grau de escolaridade dos municípios, representado pelo percentual de habitantes acima de 24 anos com ensino superior, é correlacionado positivamente com renda. Importante ressaltar que o grau de escolaridade de uma população é importante proxy 
para o desenvolvimento socioeconômico dessa, tendo, portanto, grande relação direta e indireta com seu nível de renda e de desigualdade. Estudos recentes destacam a importância das características da vizinhança na qual crianças pobres vivem na redução da probabilidade de permanência na condição de pobreza quando adultas. A qualidade da vizinhança impacta positivamente medidas subjetivas de bem-estar e saúde, enquanto que a qualidade da escola tem efeitos positivos sobre o rendimento acadêmico e salário (Fryer e Katz, 2013). Guando ponderada a concentração de domicílios nos municípios segundo seu percentual de desempregados, observa-se que, em média, esse não varia entre os grupos analisados, concentrando-se na taxa de $8 \%$, aproximadamente. Por outro lado, o percentual municipal de trabalhadores no setor informal médio para os domicílios pertencentes a cada base, apresentou tendência à queda em relação aos estratos de renda.

A distribuição dos domicílios, classificados via renda per capita, em municípios segundo seu nível de centralidade apresenta tendências de grande interesse e potencial de pesquisa, apesar de pouco exploradas na literatura. A maioria das unidades domiciliares pertence a municípios com menor nível de centralidade e, por conseguinte, provável baixo grau de dinamismo econômico. Os domicílios mais pobres tendem a se concentrar nos centros locais, enquanto que os mais ricos, nas localidades com maior grau de centralidade. Finalmente, a observação do índice de Gini municipal sugere um comportamento quadrático em relação à renda. Os domicílios analisados com rendas per capita mais elevadas e mais reduzidas encontram-se, em média, em municípios cujo índice de Gini é mais alto. Dessa forma, verifica-se que a desigualdade consiste em fator de grande relevância na determinação da pobreza. As estatísticas descritivas mostram sua importância por duas variáveis. A variância do rendimento domiciliar per capita, que reflete a distribuição desigual da renda captando efeitos locacionais e efeitos de composição domiciliar. E o índice de Gini, calculado para os municípios, que reporta a desigualdade devido às características domiciliares, pois considera-se que as locacionais estão incorporadas aos determinantes municipais. As relações entre variáveis domiciliares e locacionais com renda são exploradas nas estimações a seguir.

\subsection{Estimações por Mínimos Quadrados Ordinários}

Como primeiro exercício empírico, optou-se pelo método dos Mínimos Quadrados Ordinários. São reportados na Tabela 3 os resultados das estimações via MQO para a base completa e subamostras. Analisando o modelo de variáveis domiciliares, verificase que todas são significativas a $1 \%$ de significância e os resultados representativos da média confirmam as tendências apresentadas pela literatura, discutidas na subseção anterior. A relevância dos fatores regionais neste exercício é refletida pela significância das características municipais se mostram para a determinação de renda.

Os modelos apresentados na Tabela 3 trazem como principal contribuição a análise do comportamento da renda domiciliar per capita por decis selecionados de sua 
Tabela 1. Características domiciliares: média e desvio-padrão (Brasil, 2010)

\begin{tabular}{|c|c|c|c|c|c|c|c|c|c|}
\hline \multicolumn{2}{|l|}{ Variável } & \multicolumn{2}{|c|}{ Base completa } & \multicolumn{2}{|c|}{$20 \%$ mais pobres } & \multicolumn{2}{|c|}{ Renda mediana } & \multicolumn{2}{|c|}{$20 \%$ mais ricos } \\
\hline & & Média & DP & Média & $\mathrm{DP}$ & Média & DP & Média & $\mathrm{DP}$ \\
\hline $\begin{array}{l}\text { Renda Domicilia } \\
\text { Capita }\end{array}$ & ar Per & 944,9 & 3254,1 & 87,6 & 66,3 & 482,8 & 54,5 & 3084,2 & 6855,6 \\
\hline \multicolumn{10}{|l|}{ Sexo } \\
\hline & Masculino & 0,613 & 0,487 & 0,593 & 0,491 & 0,597 & 0,491 & 0,643 & 0,479 \\
\hline & Feminino & 0,387 & 0,487 & 0,407 & 0,491 & 0,403 & 0,491 & 0,357 & 0,479 \\
\hline \multicolumn{10}{|l|}{ Faixa Etária } \\
\hline & Abaixo de 30 anos & 0,175 & 0,380 & 0,235 & 0,424 & 0,149 & 0,356 & 0,128 & 0,334 \\
\hline & 31 a 40 anos & 0,225 & 0,417 & 0,286 & 0,452 & 0,189 & 0,391 & 0,195 & 0,396 \\
\hline & 41 a 50 anos & 0,221 & 0,415 & 0,232 & 0,422 & 0,202 & 0,402 & 0,223 & 0,417 \\
\hline & 51 a 60 anos & 0,177 & 0,381 & 0,151 & 0,358 & 0,164 & 0,370 & 0,224 & 0,417 \\
\hline & Acima de 61 anos & 0,203 & 0,402 & 0,096 & 0,294 & 0,296 & 0,457 & 0,230 & 0,421 \\
\hline \multicolumn{10}{|l|}{ Cor } \\
\hline & Brancos e Amarelos & 0,505 & 0,500 & 0,331 & 0,470 & 0,486 & 0,500 & 0,725 & 0,447 \\
\hline & Negros & 0,090 & 0,286 & 0,113 & 0,317 & 0,098 & 0,298 & 0,048 & 0,215 \\
\hline & Pardos & 0,405 & 0,491 & 0,556 & 0,497 & 0,415 & 0,493 & 0,227 & 0,419 \\
\hline \multicolumn{10}{|l|}{ Companheiro } \\
\hline & Vive com companheiro & 0,655 & 0,475 & 0,679 & 0,467 & 0,620 & 0,485 & 0,622 & 0,485 \\
\hline & Vive sem companheiro & 0,345 & 0,475 & 0,321 & 0,467 & 0,380 & 0,485 & 0,378 & 0,485 \\
\hline Moradores & & 3,306 & 1,677 & 4,146 & 1,994 & 3,044 & 1,552 & 2,642 & 1,280 \\
\hline \multicolumn{10}{|l|}{ Estudo } \\
\hline & 0 a 3 anos & 0,229 & 0,420 & 0,414 & 0,493 & 0,297 & 0,457 & 0,041 & 0,199 \\
\hline & 4 a 7 anos & 0,163 & 0,369 & 0,198 & 0,399 & 0,185 & 0,389 & 0,078 & 0,268 \\
\hline & 8 a 10 anos & 0,195 & 0,396 & 0,201 & 0,401 & 0,207 & 0,405 & 0,130 & 0,337 \\
\hline & 11 a 14 anos & 0,301 & 0,458 & 0,168 & 0,374 & 0,277 & 0,448 & 0,392 & 0,488 \\
\hline & Acima de 15 anos & 0,113 & 0,316 & 0,019 & 0,136 & 0,033 & 0,178 & 0,359 & 0,480 \\
\hline \multicolumn{10}{|l|}{ Emprego } \\
\hline & Empregado & 0,957 & 0,203 & 0,850 & 0,357 & 0,977 & 0,150 & 0,992 & 0,091 \\
\hline & Desempregado & 0,043 & 0,203 & 0,150 & 0,357 & 0,023 & 0,150 & 0,008 & 0,091 \\
\hline \multicolumn{10}{|l|}{ Urbrur } \\
\hline & Área rural & 0,860 & 0,347 & 0,699 & 0,459 & 0,872 & 0,335 & 0,966 & 0,180 \\
\hline & Área urbana & 0,140 & 0,347 & 0,301 & 0,459 & 0,128 & 0,335 & 0,034 & 0,180 \\
\hline Observações & & \multicolumn{2}{|c|}{57228224} & \multicolumn{2}{|c|}{11457056} & \multicolumn{2}{|c|}{11446446} & \multicolumn{2}{|c|}{11425728} \\
\hline
\end{tabular}

Nota: As variáveis sexo, faixa etária, cor, companheiro, estudo e emprego são referentes ao chefe de domicílio. Nas colunas são reportadas a média e o desvio-padrão da variável descrita na coluna 1. Fonte: elaboração própria a partir de dados do Censo Demográfico 2010, Estatísticas do Registro Civil 2010 e REGIC 2007 (IBGE, 2010; 2007).

distribuição. Os resultados tendem a variar de maneira informativa entre os grupos analisados. Destacam-se a relação positiva entre chefe de domicílio do sexo feminino e renda para os domicílios $20 \%$ mais pobres e negativa para os demais e a maior importância de anos de estudo, condição de ocupação do chefe e características locacionais na determinação da renda dos relativamente mais pobres em relação aos outros grupos. Os resultados refletem a perda de informação quando da análise da 
Tabela 2. Características locacionais: média e desvio-padrão (Brasil, 2010)

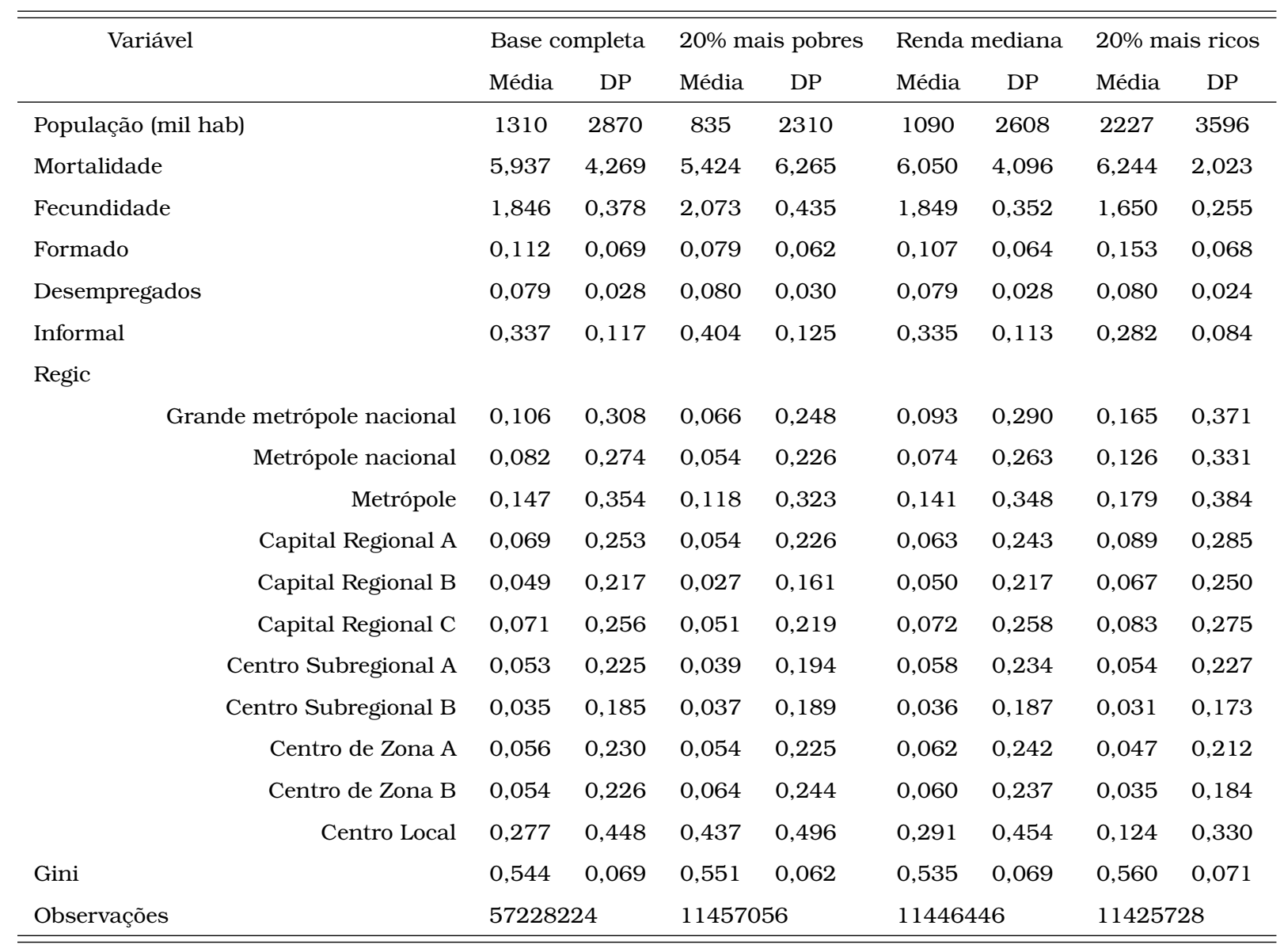

Nota: Nas colunas são reportadas a média e o desvio-padrão da variável descrita na coluna 1. Fonte: elaboração própria a partir de dados do Censo Demográfico 2010, Estatísticas do Registro Civil 2010 e REGIC 2007 (IBGE, 2010 ; 2007)

relação média entre renda e covariáveis e, concomitantemente, a capacidade elucidativa do estudo para faixas de renda do comportamento dessa segundo características domiciliares e locacionais.

Apesar de informativo e amplamente utilizado, o método de MQO pode ser limitado para a análise da relação entre renda e características domiciliares e locacionais devido à interdependência das observações intramunicipalmente e à presença de outliers. O efeito de tais características nos resultados é testado em sequência com a estimação das mesmas especificações a partir de outros métodos. 


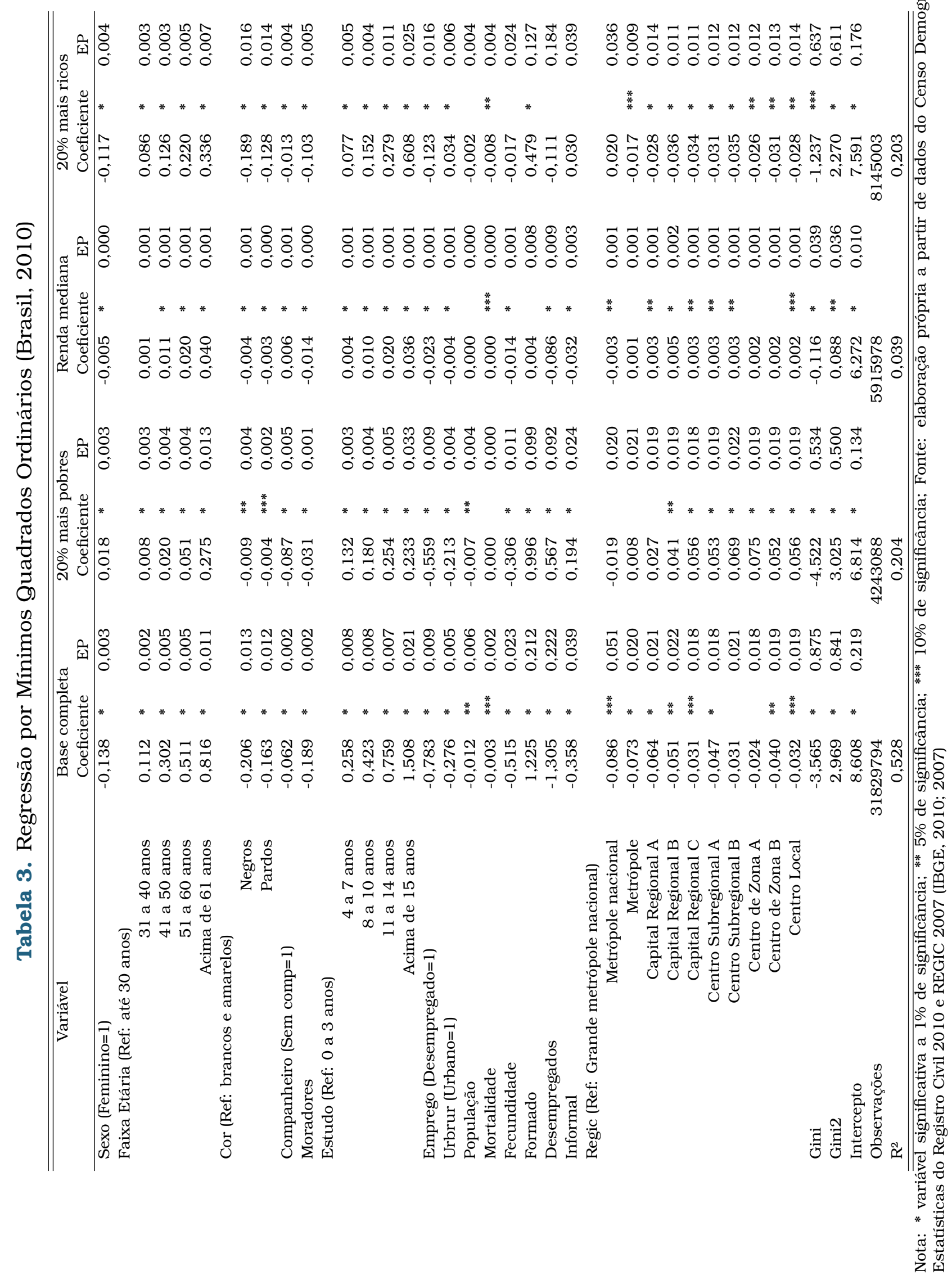




\subsection{Modelos hierárquicos}

A utilização de modelos hierárquicos, também conhecidos como modelos multiníveis, é relevante em estudos nos quais os dados apresentam padrões característicos a grupos, constituindo uma estrutura hierárquica. Nestes, o pressuposto de independência das observações não é observado, sendo essas correlacionadas segundo o agrupamento (Hox, 1998). Os modelos hierárquicos, ao contrário dos modelos estimados via Mínimos Quadrados Ordinários, ponderam a dependência intragrupo das variáveis permitindo a variação dos coeficientes explorados em nível domiciliar segundo as características locacionais, como estruturado na seção metodológica.

Tabela 4. Análise de variância (Brasil, 2010)

\begin{tabular}{lrrrrrrrr}
\hline \hline \multirow{2}{*}{ Estimativas } & \multicolumn{2}{c}{ Base completa } & \multicolumn{2}{c}{ 20\% mais pobres } & \multicolumn{2}{c}{ Renda mediana } & \multicolumn{2}{c}{ 20\% mais ricos } \\
& Valor & $\mathrm{EP}$ & Valor & $\mathrm{EP}$ & Valor & $\mathrm{EP}$ & Valor & EP \\
\hline Variância & & & & & & & & \\
Intermunicipal & 0,508 & 0,005 & 0,231 & 0,002 & 0,007 & 0,000 & 0,126 & 0,002 \\
Intramunicipal & 0,953 & 0,000 & 0,682 & 0,000 & 0,115 & 0,000 & 0,602 & 0,000 \\
ICC & 0,348 & & 0,253 & & 0,061 & & 0,173 & \\
& & & & & & & & \\
Constante & 5,811 & 0,007 & 4,566 & 0,003 & 6,176 & 0,000 & 7,651 & 0,000 \\
Observações & 5845192 & & 1147952 & & 1278371 & & 962098 & \\
\hline \hline
\end{tabular}

Fonte: Elaboração própria a partir de dados do Censo Demográfico 2010, Estatísticas do Registro Civil 2010 e REGIC 2007 (IBGE, 2010; 2007).

Os resultados da análise de variância, apresentados na Tabela 4, reportam que parcela importante da variância da renda, aproximadamente 35\%, é explicada pelas diferenças intermunicipais para a amostra completa. Para o grupo dos domicílios $20 \%$ mais pobres, $25 \%$ da variância é explicada pela variabilidade das características locacionais. Essa proporção é de 6,1\% para os de renda mediana e de 17,3\% para os 20\% mais ricos. Essas estimativas retornam que as características locacionais têm maior participação na determinação da renda domiciliar per capita dos $20 \%$ mais pobres e dos $20 \%$ mais ricos do que dos domicílios com renda próxima à mediana. Ademais, verifica-se que a participação da variância intermunicipal é reduzida para subamostras, ou seja, há uma diminuição do ICC. Tal resultado sugere que o recorte por faixas de renda capta parcialmente a variabilidade locacional, reforçando a importância da relação renda e características locacionais.

A Tabela 5 compreende os modelos hierárquicos com regressores em dois níveis, o de menor agregação, domiciliar, e o de maior agregação, municipal. Em primeiro lugar, observa-se que a relação entre renda domiciliar per capita e covariáveis é muito distinta entre as faixas de renda. Em segundo lugar, observa-se que as tendências associadas aos coeficientes locacionais e à variável urbano, diferem significativamente daquelas estimadas via MQO. Como discutido na seção metodológica e anteriormente 
nessa subseção, nos MHL os coeficientes são estimados a partir da interação entre as variáveis domiciliares e locacionais. Dessa forma, a diferença encontrada elucida sobre a importância da aplicação de especificações e/ou métodos que ponderem a estrutura da relação entre renda e características locacionais.

Tabela 5. Modelos hierárquicos (Brasil, 2010)

\begin{tabular}{|c|c|c|c|c|c|c|c|c|c|}
\hline \multirow{3}{*}{$\begin{array}{l}\text { Variável } \\
\text { Sexo }(\text { Feminino=1) }\end{array}$} & \multicolumn{3}{|c|}{$20 \%$ mais pobres } & \multicolumn{3}{|c|}{ Renda mediana } & \multicolumn{3}{|c|}{$20 \%$ mais ricos } \\
\hline & \multicolumn{2}{|c|}{ Coeficiente } & \multirow{2}{*}{$\begin{array}{c}\mathrm{EP} \\
0,002\end{array}$} & \multicolumn{2}{|c|}{ Coeficiente } & \multirow{2}{*}{$\frac{\mathrm{EP}}{0,000}$} & \multicolumn{2}{|c|}{ Coeficiente } & \multirow{2}{*}{$\frac{\mathrm{EP}}{0,002}$} \\
\hline & 0,023 & $*$ & & $-0,005$ & $*$ & & $-0,119$ & $*$ & \\
\hline \multicolumn{10}{|l|}{ Faixa Etária (Ref: até 30 anos) } \\
\hline 31 a 40 anos & 0,014 & $*$ & 0,002 & 0,002 & $*$ & 0,000 & 0,083 & $*$ & 0,002 \\
\hline 41 a 50 anos & 0,028 & * & 0,002 & 0,014 & $*$ & 0,000 & 0,126 & * & 0,002 \\
\hline 51 a 60 anos & 0,068 & * & 0,003 & 0,022 & * & 0,001 & 0,216 & * & 0,002 \\
\hline Acima de 61 anos & 0,338 & $*$ & 0,005 & 0,045 & * & 0,001 & 0,318 & * & 0,003 \\
\hline \multicolumn{10}{|l|}{ Cor (Ref: brancos e amarelos) } \\
\hline Negros & $-0,009$ & * & 0,003 & $-0,006$ & * & 0,001 & $-0,172$ & * & 0,003 \\
\hline Pardos & $-0,009$ & $*$ & 0,002 & $-0,005$ & $*$ & 0,000 & $-0,118$ & * & 0,002 \\
\hline Companheiro (Sem comp=1) & $-0,075$ & * & 0,003 & 0,006 & * & 0,000 & $-0,006$ & $*$ & 0,002 \\
\hline Moradores & $-0,035$ & $*$ & 0,000 & $-0,015$ & * & 0,000 & $-0,093$ & * & 0,001 \\
\hline \multicolumn{10}{|l|}{ Estudo (Ref: 0 a 3 anos) } \\
\hline 4 a 7 anos & 0,129 & * & 0,002 & 0,005 & * & 0,001 & 0,089 & * & 0,004 \\
\hline 8 a 10 anos & 0,184 & * & 0,002 & 0,011 & $*$ & 0,001 & 0,155 & * & 0,004 \\
\hline 11 a 14 anos & 0,273 & $*$ & 0,003 & 0,021 & $*$ & 0,001 & 0,261 & * & 0,004 \\
\hline Acima de 15 anos & 0,334 & * & 0,010 & 0,038 & $*$ & 0,001 & 0,557 & * & 0,004 \\
\hline Emprego (Desempregado=1) & $-0,581$ & * & 0,003 & $-0,023$ & * & 0,001 & $-0,105$ & * & 0,008 \\
\hline Urbrur (Urbano=1) & $-0,213$ & $*$ & 0,002 & $-0,005$ & $*$ & 0,000 & 0,042 & $*$ & 0,003 \\
\hline Constante & 4,807 & $*$ & 0,005 & 6,187 & $*$ & 0,001 & 7,426 & $*$ & 0,005 \\
\hline População & 0,006 & $*$ & 0,001 & 0,001 & $*$ & 0,000 & 0,006 & $*$ & 0,000 \\
\hline Mortalidade & 0,008 & $*$ & 0,001 & 0,001 & $*$ & 0,000 & 0,009 & $*$ & 0,000 \\
\hline Fecundidade & 0,033 & $*$ & 0,004 & 0,003 & $*$ & 0,000 & 0,028 & $*$ & 0,001 \\
\hline Formado & 0,429 & $*$ & 0,065 & 0,047 & $*$ & 0,007 & 0,582 & $*$ & 0,040 \\
\hline Desempregados & 0,654 & $*$ & 0,058 & 0,07 & $*$ & 0,006 & 0,813 & * & 0,042 \\
\hline Informal & 0,159 & * & 0,011 & 0,015 & * & 0,001 & 0,152 & * & 0,007 \\
\hline \multicolumn{10}{|l|}{ Regic (Ref: Grande metrópole nacional) } \\
\hline Metrópole nacional & 0,126 & & 0,114 & 0,129 & & 0,138 & 0,138 & * & 0,050 \\
\hline Metrópole & 0,053 & * & 0,019 & 0,262 & & 0,242 & 0,179 & * & 0,026 \\
\hline Capital Regional A & 0,393 & * & 0,097 & 0,141 & $* *$ & 0,071 & 0,111 & * & 0,026 \\
\hline Capital Regional B & 0,188 & & 0,135 & 0,187 & & 0,134 & 0,083 & $*$ & 0,024 \\
\hline Capital Regional C & 0,140 & $*$ & 0,027 & 0,201 & & 0,156 & 0,253 & & 0,246 \\
\hline Centro Subregional A & 0,052 & $* *$ & 0,022 & 0,143 & $* *$ & 0,068 & 0,111 & $*$ & 0,020 \\
\hline Centro Subregional B & 0,088 & $*$ & 0,025 & 0,015 & $*$ & 0,003 & 0,007 & & 0,016 \\
\hline Centro de Zona A & 0,023 & & 0,017 & 0,183 & $*$ & 0,069 & 0,123 & * & 0,014 \\
\hline Centro de Zona B & 0,596 & $*$ & 0,056 & 0,289 & & 0,191 & 0,501 & * & 0,051 \\
\hline Centro Local & 0,095 & $*$ & 0,008 & 0,009 & $*$ & 0,000 & 0,073 & $*$ & 0,003 \\
\hline Gini & 0,134 & $*$ & 0,015 & 0,012 & $*$ & 0,001 & 0,117 & $*$ & 0,006 \\
\hline Gini2 & 0,267 & $*$ & 0,038 & 0,022 & $*$ & 0,002 & 0,223 & $*$ & 0,011 \\
\hline Intercepto & 0,066 & * & 0,006 & 0,006 & $*$ & 0,000 & 0,059 & $*$ & 0,003 \\
\hline Observações & 4243088 & & & 5915978 & & & 8145003 & & \\
\hline
\end{tabular}

Nota: * variável significativa a 1\% de significância; ** $5 \%$ de significância; *** $10 \%$ de significância; Fonte: elaboração própria a partir de dados do Censo Demográfico 2010, Estatísticas do Registro Civil 2010 e REGIC 2007 (IBGE, 2010; 2007) 


\subsection{Regressões quantílicas}

A seguir, são apresentados os resultados dos modelos de regressão quantílica para os decis limítrofes das subamostras trabalhadas, a saber: segundo, quarto, sexto e oitavo decil. Em primeiro lugar, reitera-se a relevância da relação entre renda e características locacionais devido à significância destes últimos, como nas estimações anteriores. A literatura acerca de pobreza destaca a importância da estrutura produtiva urbana, do desenvolvimento do mercado de trabalho, do nível de desigualdade local e da oferta de serviços públicos de qualidade, especialmente em educação e saúde, na redução da condição de privação (Fontes, 2006; Hulme et al., 2001; Soares, 2009).

Destaca-se que os coeficientes não apresentam variações de sinal entre os quantis, ao contrário do que ocorre para os modelos hierárquicos e MQO entre as subamostras. As regressões reportadas na Tabela 6 apresentam também menor disparidade dos coeficientes entre os quantis de renda do que as anteriores. Essas constituem evidências de que os coeficientes estimados nas regressões anteriores respondem de maneira importante à presença de outliers. Nas regressões quantílicas, os coeficientes são estimativas do efeito marginal de uma variação na variável independente sobre o quantil da variável dependente condicional às demais observáveis. Nos modelos hierárquicos e estimados via $\mathrm{MQO}$, os coeficientes são estimativas do efeito marginal de uma variação na variável independente sobre o valor da variável dependente condicional às demais observáveis.

Como nas estimações pelas metodologias anteriores, observa-se uma importante diferença dos coeficientes estimados entre os decis de interesse, embora menor para as regressões quantílicas. Em especial, a renda per capita dos mais pobres se mostra mais sensivel ao número de moradores, à presença de um companheiro do chefe de domicílio e à sua condição de ocupação, assim como à taxa de desemprego e informalidade do município.

A partir das estimações via Mínimos Quadrados Ordinários, modelos hierárquicos e regressões quantílicas, conclui-se em primeiro lugar que as variáveis locacionais explicam relevante parcela da variação da renda domiciliar per capita. Desse modo, faz-se importante a consideração da relação entre renda e características locacionais na especificação e na estrutura da variância, podendo ser informativo o uso de modelos multiniveis - apesar de não ser estritamente necessária quando a especificação incluir observáveis municipais. Em segundo lugar, verifica-se que a relação entre renda domiciliar per capita e fatores locacionais e domiciliares é heterogênea ao longo da distribuição desta, sendo a análise para grupos de renda fortemente informativa. Em terceiro lugar, a comparação dos resultados das regressões quantílicas com as demais, sugere que a presença de outliers nos extremos da distribuição de renda afeta significativamente a relação entre esta e as variáveis independentes, sendo seguro explorar metodologias robustas a outliers como robustez. 


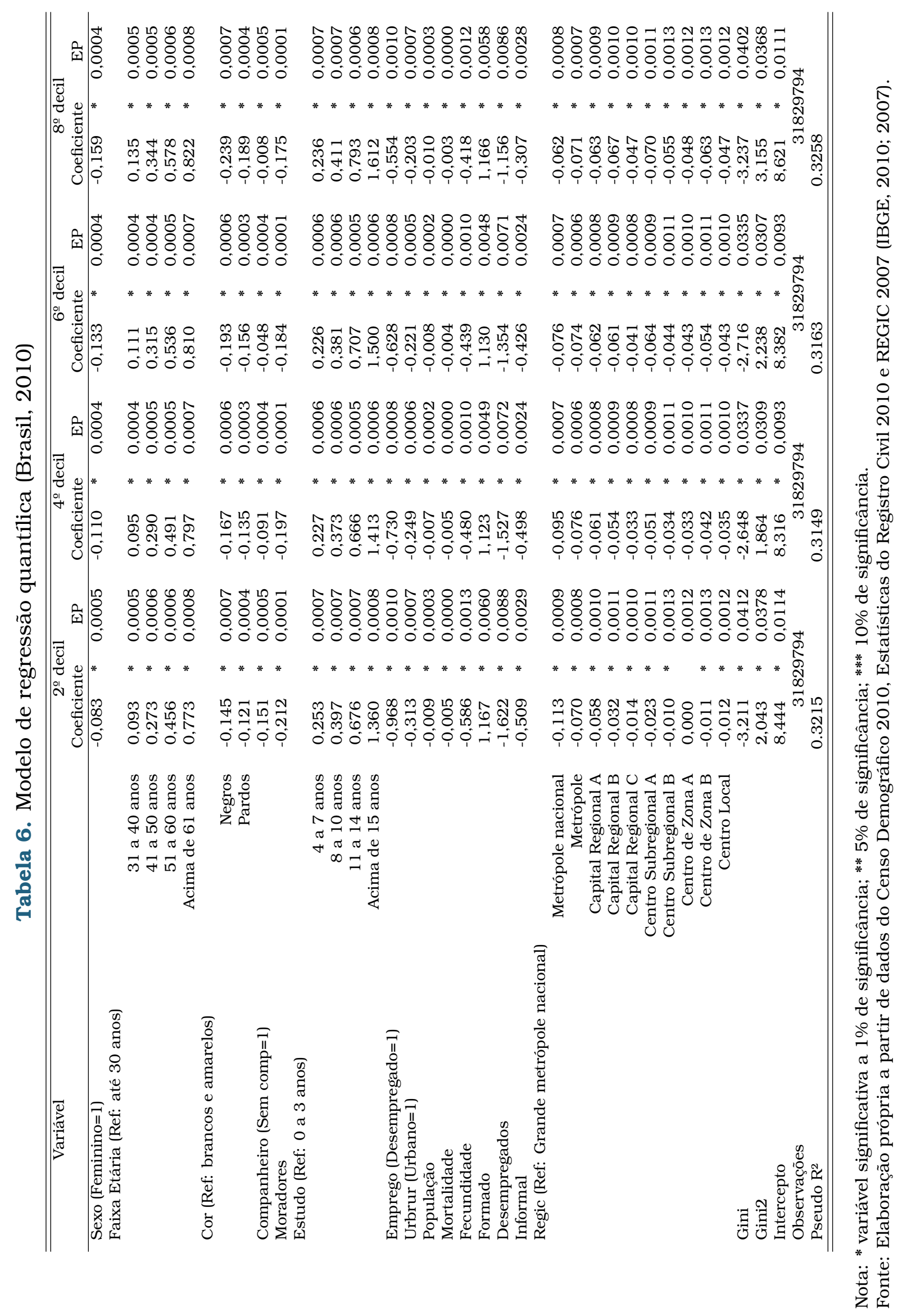


Desse modo, os resultados obtidos via MQO, MHL e regressão quantílica mostramse complementares uma vez que são capazes de lidar de maneira diferente com aspectos da relação renda e características domiciliares e locacionais. A análise específica de cada determinante da renda é apresentada na subseção seguinte.

\subsection{Análise dos determinantes da pobreza}

Nesta subseção, são discutidos os determinantes da renda domiciliar per capita dos relativamente mais pobres, ou seja, dos domicílios com renda abaixo do segundo decil. As diferentes metodologias traçam perfis bem delineados para a pobreza no tocante às características domiciliares. Para as características locacionais, no entanto, tendências diferenciam-se por vezes entre os métodos aplicados. Dessa forma, a análise dos determinantes da pobreza é majoritariamente baseada nos resultados do modelo quantílico para lidar com a influência dos outliers de renda nas regressões. Seus coeficientes refletem o efeito marginal da variável independente sobre o quantil da variável dependente, sendo menos suscetível à existência de observações discrepantes nos extremos da distribuição de renda. Ao contrário dos modelos hierárquicos, as regressões quantílicas não permitem a estimação de coeficientes aleatórios para cada variável domiciliar segundo as características municipais, que se mostrou um exercício empírico informativo. Contudo, a inclusão dos fatores locacionais nos modelos irrestritos é satisfatória para a ponderação de sua influência na determinação de renda, sendo tal estratégia mais utilizada na literatura do que a estimação de MHL.

Em primeiro lugar, verifica-se que domicílios com chefe do sexo feminino, cerca de $39 \%$ do total, têm menor renda per capita em média. A diferença da renda domiciliar per capita de domicílios com chefe do sexo masculino para domicílios com chefe do sexo feminino é maior para níveis de renda mais altos. Segundo Barros et al. (1997), o número de domicílios chefiados por mulheres está aumentando em nível mundial e nacional desde a segunda metade do século XX. A determinação do chefe de domicilio está fortemente correlacionada à participação do membro na renda domiciliar total (Rocha, 2006). Em segundo lugar, domicílios chefiados por pessoas mais velhas têm maior renda per capita. Esse padrão é mais acentuado dentre os mais pobres, apesar desse grupo ser caracterizado pela predominância de chefes mais jovens. Esse resultado é condizente com a discussão da importância relativa da renda do chefe em paralelo às evidências empíricas da relação majoritariamente positiva e côncava entre experiência/idade no mercado de trabalho e salário, o que explica especialmente a importância da idade dentre os chefes mais pobres e mais jovens (Heckman et al., 2003; Card e Dinardo, 2002). Quanto à cor, existe uma concentração significativamente maior de chefes negros ou pardos dentre os mais pobres, como reportado na Tabela 1. Domicílios com chefes negros ou pardos apresentam menor renda per capita, inclusive dentre os $20 \%$ mais pobres, o que a literatura associa em grande parte à desigualdade de oportunidades racial e à discriminação no mercado de trabalho (Campante et al., 2004; Osorio, 2021). 
Quanto ao par, verificou-se que domicílios cujos chefes vivem com um cônjuge ou companheiro representam $66 \%$ do total. Para os mais pobres, especialmente, a presença de um companheiro é fator crucial na determinação da renda domiciliar per capita, sendo mais importante do que fatores como cor ou sexo do chefe. Segundo Rocha (2006), são mais vulneráveis famílias uniparentais. Outro importante determinante da renda é o número de moradores no domicílio, sendo estas variáveis negativamente correlacionadas em todas as subamostras. Dentre as variáveis de maior correlação com renda, estão as categorias de anos de estudo do chefe, resultado encontrado em diversos estudos empíricos (Heckman et al., 2003; Ferreira et al., 2006). Predominantemente, os chefes dos domicílios $20 \%$ mais pobres têm menos de 7 anos de estudo, enquanto que os chefes dos $20 \%$ mais ricos têm 11 ou mais anos de estudo. A relação entre escolaridade e renda é crescente para toda a amostra, sendo mais forte para os extremos de renda.

Por sua vez, a situação empregatícia do chefe mostrou-se a variável mais importante para a determinação da renda dos $20 \%$ mais pobres, sendo também de grande relevância para os demais. Domicílios cujo chefe encontra-se desempregado têm renda menor do que aqueles com chefe empregado, como esperado. Domicílios que se encontram em zonas rurais têm também, em média, menor renda domiciliar per capita do que os que se encontram em áreas urbanas mesmo após o controle por observáveis de desenvolvimento local, o que remete à desigualdade de oportunidades que atinge os moradores de zona rurais e reflete em parte o menor custo de vida dessas áreas sobre renda (Barros et al., 2008). Essa relação é mais intensa para os decis mais baixos de renda.

Em relação aos determinantes locacionais, têm renda per capita significativamente maior domicílios localizados em municípios com menor população, menor taxa de fecundidade e menor taxa de mortalidade, reflexo da importância dos determinantes de saúde e bem-estar local sobre os domicílios. Andrade et al. (2013) discutem a relação entre saúde individual e nível de renda, a melhoria no acesso a serviços de saúde no Brasil nas últimas décadas e a redução da desigualdade regional neste aspecto. O percentual de moradores acima de 24 anos do município com ensino superior também é altamente correlacionado com renda, indicando que localidades com alto potencial de formação e/ou atração de capital humano tendem a ter maior nível de renda. A persistência das diferenças regionais na composição educacional da força de trabalho é um dos principais determinantes das desigualdades por região (REIS, BARROS, 1989). Ademais, têm maior renda per capita aqueles domicílios localizados em municípios com menor taxa de desemprego e com menor percentual de trabalhadores informais, o que reflete a importância do mercado de trabalho local, em especial o formal, na redução da pobreza para o contexto brasileiro. Ulyssea (2007) analisa a importância da segmentação espacial, setorial e formal-informal na evolução da desigualdade da renda do trabalho no Brasil. Segundo o estudo, a segmentação formal-informal constitui um dos seus principais determinantes, sendo um fator de agravamento da desigualdade nos anos 2000, enquanto a maior integração do mercado de trabalho 
entre municípios e a redução do diferencial salarial entre os setores agrícolas e os demais favoreceram sua redução.

Em relação à classificação REGIC, apresentam maior renda per capita domicílios localizados em municípios pertencentes a grandes metrópoles nacionais, fator fortemente correlacionado com nível de preços. Desconsiderando aqueles pertencentes às grandes metrópoles, apresentam maior renda per capita domicílios localizados em municípios com menor grau de centralidade. Essa não é uma relação estrita, no entanto. Nesse sentido, Fontes (2006) destaca a importância dos fatores econômicos locais relacionados em especial à dinâmica produtiva na determinação da renda do trabalho. De modo geral, domicílios pobres e ricos se concentram em municípios com maior grau de desigualdade. Em todos os modelos analisados, a relação entre renda e desigualdade mostrou-se majoritariamente decrescente e côncava, como bem estabelecido na literatura do tema (Barros et al., 1997).

Desse modo, verifica-se a interrelação entre renda domiciliar per capita e determinantes do desenvolvimento socioeconômico, como taxa de mortalidade, grau de informalidade e capital humano. A importância de políticas de promoção do desenvolvimento humano e do mercado de trabalho local é reiterada como meio efetivo de redução da pobreza.

\section{Conclusão}

Este trabalho realiza um estudo do comportamento da renda domiciliar per capita para diferentes contextos socioeconômicos, visando o entendimento do papel das dissimilaridades locacionais, especialmente sobre pobreza. As conclusões deste trabalho podem ser associadas a três grandes linhas de análise, discutidas nesta seção. A primeira, consiste na investigação da importância da ponderação de variáveis locacionais quando estudado o comportamento da renda. Verificou-se a sensibilidade das estimações à inclusão de características municipais nos modelos e significativa correlação destes com renda domiciliar per capita. A relevância dos aspectos locacionais reitera a necessidade do uso de especificações e/ou métodos que ponderem a interdependência locacional dos domicílios.

A segunda linha de análise tem como enfoque a heterogeneidade da relação entre renda domiciliar per capita e características domiciliares e locacionais ao longo da distribuição de renda. As estimações aplicadas separadamente para diferentes faixas de renda se mostraram significativamente distintas. Da mesma forma, aquelas estimadas a partir de metodologias robustas a outliers, regressão quantílica, trouxeram relações entre a variável dependente e as covariáveis diferentes das demais, MQO e modelagem multinível. Portanto, conclui-se que, a depender do objetivo da análise, o comportamento médio das características de interesse pode ser pouco elucidativo, assim como a utilização de metodologias muito sensiveis a outliers para estudo de as- 
pectos relativos à renda. A análise da relação entre aspectos domiciliares/locacionais e renda para diferentes faixas desta faz-se muito informativa, especialmente para o delineamento de políticas públicas de combate à pobreza.

Aos esforços anteriores, soma-se o de análise dos determinantes domiciliares e locacionais de renda, com enfoque nos domicílios relativamente mais pobres. A relação entre renda e características locacionais explica aproximadamente 35\% da variância da renda domiciliar per capita. Verifica-se que o percentual de moradores acima de 24 anos do município com ensino superior é altamente correlacionado com renda, indicando que localidades com alto potencial de formação e atração de capital humano tendem a ter maior nivel de renda. Observa-se que domicílios localizados em municípios com alta taxa de mortalidade, fecundidade, desemprego e trabalhadores informais apresentam menor renda per capita do que os demais. Por sua vez, domicílios localizados em municípios com menor grau de centralidade apresentam em média maior rendimento per capita, à exceção dos domicílios localizados em grandes metrópoles nacionais, cujos rendimentos mostram-se maiores - resultado esperado devido ao elevado custo de vida dessas localidades. Os resultados são consistentes com evidências da literatura sobre privação.

Dessa forma, buscou-se elucidar a importância da ponderação das características locacionais no estudo do comportamento da renda domiciliar per capita, evidenciar a heterogeneidade da relação desta com aspectos domiciliares e municipais e delinear tendências associadas à pobreza relativa no Brasil. A relevância das diferenças locacionais na determinação do nível de renda recrudesce a importância da interação de políticas de desenvolvimento regional, em especial daquelas de impacto em saúde e educação e de promoção do mercado de trabalho formal local, com políticas diretas de redução da vulnerabilidade das famílias, da desigualdade de oportunidades e da discriminação no mercado de trabalho no combate à pobreza.

\section{Referências}

Andrade, M., Noronha, K., Menezes, R., Souza, M., Reis, C., Martins, D., Gomes, L. (2013). Desigualdade socioeconômica no acesso aos serviços de saúde no Brasil: um estudo comparativo entre as regiões brasileiras em 1998 e 2008. Economia Aplicada, $17(3): 265-281$.

Arbache, J. (2003). Pobreza e mercados no Brasil. In: Nações Unidas. CEPAL. Pobreza e mercados no Brasil: uma análise de iniciativas de políticas públicas. Brasília. CEPAL.

Assouad, L., Chancel, L., Morgan, M. (2018). Extreme Inequality: Evidence from Brazil, India, the Middle East, and South Africa. AEA Papers and Proceedings.

Barros, R., Ferreira, F., Veja, J., Chanduvi, J. (2008). Measuring Inequality of Opportunities in Latin America and the Caribbean. The World Bank. 
Barros, R., Henriques, R., Mendonça, R. (2000). Estabilidade Inaceitável: Desigualdade e Pobreza no Brasil. In: R. Henriques, R. (Org.). Desigualdade e Pobreza no Brasil. Rio de Janeiro: IPEA.

Barros, R., Fox, L., Mendonça, R. (1997). Female-headed households, poverty, and the welfare of children in urban Brazil. Economic Development and Cultural Change.

Barros, R, Mendonça, R. (1995) A evolução do bem-estar, pobreza e desigualdade no Brasil ao longo das últimas três décadas - 1960/90. Pesquisa e Planejamento Econômico, 25(1):115-164.

Barros, R, Mendonça, R. (1997). Bem-Estar, Pobreza e Desigualdade de Renda: Uma Avaliação da Evolução Histórica e das Disparidades Regionais. Rio de Janeiro: IPEA.

Brasília. (2011). Governo Federal. Secretaria de Assuntos Estratégicos. Comissão para Definição da Classe Média. Disponível em: <http://www.sae.gov.br/site/?p=13425>.

Campante, F., Crespo, A., Leite, P. (2004). Desigualdade salarial entre raças no mercado de trabalho urbano brasileiro: aspectos regionais. Revista Brasileira de Economia, 58(2):56-72.

Card, D., Dinardo, J. (2002). Skill-Biased Technological Change and Rising Wage Inequality: Some Problems and Puzzles. Journal of Labor Economics, 20:733-783.

Chetty, R.; Hendren, N.; Katz, L. (2016). The effects of exposure to better neighborhoods on children: New evidence from the Moving to Opportunity experiment. American Economic Review, 106(4):855-902.

Chetty, R., Hendren, N., Kline, P., Saez, E. (2014). Where is the land of opportunity? The geography of intergenerational mobility in the United States. Quarterly Journal of Economics, 129(4):1553-1623.

Dedecca, C. (2015). A redução da desigualdade e seus desafios. Rio de Janeiro, IPEA.

Ferreira, F., Leite, P., Litchfield, J. (2006). The rise and fall of Brazilian inequality: 1981-2004. Washington, DC, World Bank.

Fontes, G. (2006). Atributos urbanos e diferenciais regionais de salário no Brasil, 1991 e 2000. Dissertação (Mestrado em Economia) - Centro de Desenvolvimento e Planejamento Regional, Universidade Federal de Minas Gerais, Belo Horizonte.

Fryer, R., Katz, L. (2013). Achieving Escape Velocity: Neighborhood and School Interventions to Reduce Persistent Inequality. American Economic Review: Papers \& Proceedings, 103(3):232-237.

Haughton, J., Khandker, S. (2009). Handbook on Poverty and Inequality. Washington, DC: World Bank.

Heckman, J., Lance, L., Todd, P. (2003). Fifty Years of Mincer Earnings Regressions. 
NBER, Working Paper n. 9732.

Hox, J. (1995). Applied Multilevel Analysis. Amsterdam, TT-Publikaties.

Hox, J. (1998). Multilevel modeling: when and why. In: Balderjahn, I., Mathar, M., Schader, M. (Eds.). Classification, data analysis, and data highways. Nova Iorque, Springer Verlag. p.147-154.

Hulme, D., Mooren, K., Shepherd, A. (2001). Chronic poverty: meanings and analytical frameworks. Manchester: IDPM, University of Manchester (CPRC Working Paper 2).

IBGE. (2012). Censo Demográfico 2010. Rio de Janeiro, IBGE, 2010.

IBGE. (2010). Estatísticas do Registro Civil 2010. Rio de Janeiro, IBGE.

IBGE. (2007). Regiões de Influência das Cidades 2007. Rio de Janeiro, IBGE.

IPEA. (2013). Um retrato de duas décadas do mercado de trabalho brasileiro utilizando a PNAD. Rio de Janeiro, IPEA. (Comunicados do IPEA, n.160)

Jalan, J., Ravallion, M. (2000). Is transient poverty different? Evidence for rural China. Journal of Development Studies, 36(1):82-99.

Lustig, N, Lopez-Calva, L, Ortiz-Juarez, E. (2013). Declining Inequality in Latin America in the 2000s: The Cases of Argentina, Brazil, and Mexico. World Development,36(4):435456.

Lustig, N, Pessino, C, Scott, J. (2014). The Impact of Taxes and Social Spending on Inequality and Poverty in Argentina, Bolivia, Brazil, Mexico, Peru, and Uruguay: Introduction to the Special Issue. Public Finance Review, 42(3):287-303.

Menezes, T., Azzoni, C, Moreira, G. (2007). Diferenças em gastos com aluguel entre estados, tipos de área e níveis de renda familiar no Brasil. Brasília: IPEA.

Neri, M. (2007). Pobreza e políticas sociais na década da redução da desigualdade.Nueva Sociedad, 65(1):53-75.

Osorio, R. (2003) O Sistema classificatório de "cor ou raça" do IBGE. Brasília, Instituto de Pesquisa Econômica Aplicada. (Texto para Discussão, 996).

Osorio, R. G. (2021). A Desigualdade racial no Brasil nas três últimas décadas. Brasília, Instituto de Pesquisa Econômica Aplicada. (Texto para Discussão, 2657).

Ravallion, M. (2012). Why Don't We See Poverty Convergence? American Economic Review, 102(1):504-523.

Reis, J., Barros, R. (1989). Um estudo da evolução das diferenças regionais da desigualdade no Brasil. IPEA.

Rocha, S. (2006). Pobreza no Brasil: afinal de que se trata?. Rio de Janeiro: FGV. 
Soares, S. (2009). Metodologias para Estabelecer a Linha de Pobreza: objetivas, subjetivas, relativas, multidimensionais. Rio de Janeiro, IPEA. (Texto para discussão, n.1381)

Souza, P. H., Osorio, R. G., Paiva, L. H., Soares, S. (2021). Os efeitos do Programa Bolsa Família sobre a pobreza e a desigualdade: um balanço dos primeiros quinze anos. Brasília, Instituto de Pesquisa Econômica Aplicada. (Texto para Discussão, 2499)

Tian, M., Chen, G. (2006). Hierarchical linear regression models for conditional quantiles. Science in China: Series A Mathematics, 49(12):1800-1815.

Townsend, P. (1993). The International Analysis of Poverty. Hertfordshire, Harvester Wheatsheaf.

Townsend, P. (1962). The meaning of poverty. British Journal of Sociology, 12(2):54-71.

Ulyssea, G. (2007). Segmentação no mercado de trabalho e desigualdade de rendimentos no Brasil: uma análise empírica. Rio de Janeiro, IPEA. (Texto para discussão, n.1261)

@Er Este artigo está licenciado com uma CC BY 4.0 license. 